\title{
In situ non-invasive multianalytical methodology to characterize mosaic tesserae from the House of Gilded Cupids, Pompeii
}

\author{
Iker Marcaida ${ }^{1 *}(0)$, Maite Maguregui ${ }^{2}$, Héctor Morillas ${ }^{1}$, Nagore Prieto-Taboada ${ }^{1,2}$, Marco Veneranda $^{3}$, \\ Silvia Fdez-Ortiz de Vallejuelo ${ }^{1}$, Alberta Martellone ${ }^{4}$, Bruno De Nigris ${ }^{4}$, Massimo Osanna ${ }^{5}$ \\ and Juan Manuel Madariaga ${ }^{1,6}$
}

\begin{abstract}
Mosaics, one of the most important decorative artworks in the Roman culture, were usually elaborated with a set of tesserae joined with lime or others binders to form geometric or figurative decorations. The identification of both substrate and colored compounds of the tesserae is a challenge for chemists and archaeologists. In this work, two mosaics present in the House of Gilded Cupids from the Archaeological Park of Pompeii were analyzed in situ by non destructive techniques. Raman and Diffuse Reflectance Infrared Fourier Transform (DRIFT) spectroscopies were used for the molecular and mineralogical characterization, and hand-held energy dispersive $\mathrm{X}$-ray fluorescence (HH-EDXRF) spectrometry and Laser Induced Breakdown Spectroscopy (LIBS) for the elemental analysis. LIBS in-depth analysis was performed to obtain insights about the thickness of the pictorial layer determining that the thickness of red and orange pictorial layers was higher than $140 \mu \mathrm{m}$. The results showed that white tesserae were mainly composed by calcite, while local black colored volcanic rocks were used to manufacture black tesserae. Red and orange tesserae were composed by a calcite-based matrix with a hematite pictorial layer applied over it. Orange color was obtained by diluting hematite in the calcite matrix. Principal component analysis (PCA) of the XRF data was performed to observe differences and/or similarities between the analyzed mosaics; the samples projection of the PCA showed clear groupings.
\end{abstract}

Keywords: Pompeian mosaics, X-ray fluorescence spectrometry, LIBS, Raman spectroscopy, Diffuse reflectance infrared Fourier transform spectroscopy, Local black colored volcanic rock

\section{Introduction}

Pompeii preserves one of the most important archaeological remains of the world. In this Archaeological Park sculptures, relics, jewellery, paintings, and mosaics, among many other archaeological records can be found. Nowadays many of the recovered artworks and objects are stored in the Naples National Archaeological Museum (MANN) for their correct preservation. In the literature, there are works dealing with the analysis of

\footnotetext{
*Correspondence: iker.marcaida@ehu.es

1 Department of Analytical Chemistry, Faculty of Science and Technology, University of the Basque Country UPV/EHU, P.O. Box 644, 48080 Bilbao, Basque Country, Spain

Full list of author information is available at the end of the article
}

pigments and wall paintings conserved in this museum [1-6], but there is a lack of works about mosaics in comparison with other archaeological records.

When the Romans conquered the region of Greece during the second century $\mathrm{BC}$, mosaic works were already common in the Greek world. Thereby, the art of the mosaics easily passed to the Roman culture giving way to an artistic-industrial genre. It was spread in such a way that there were almost not houses or Roman villas without mosaics. The Roman mosaics are easy to discover for archaeologists and so far their number is very high, but they present a great difficulty of conservation.

In this sense, in the surroundings of Pompeii, specifically in the Bay of Naples area, a great number of mosaics were discovered. This area is rich in archaeological sites 
due to the closeness to Mount Vesuvius, because several ancient cities were buried after the eruption event occurred in year 79 AD. Apart from Pompeii, probably the most famous archaeological park of the area, other archaeological sites such as Herculaneum or Stabiae can be found. Many mosaics located in the Bay of Naples have been analyzed in the laboratory with the purpose of identifying the materials used for their manufacture or to determine the provenance of the materials used [711]. Therefore, mosaics can be considered as one of the most used and important decorative patterns in Ancient Roman cities, and consequently, also in the Bay of Naples and surroundings of Mount Vesuvius.

The archaeological excavations carried out in Pompeii allowed the recovery of mosaics in excellent state of preservation, but the numerous processes of degradations that are usually activated in the post-excavation phase require the application of periodic maintenance treatments. Considering that these deterioration mechanisms are usually associated with weathering phenomena, the ideal place to store the mosaics is in museums where temperature, humidity, etc., are under control.

A mosaic is a pictorial work elaborated with a set of tesserae joined between them by lime [11] or other binders to form geometric or figurative decorative compositions. A tessera is an individual piece of cubic form, made of calcareous rocks, glass or ceramic material [12]. The ancient artists used to arrange them into representational designs and geometric patterns. The tesserae used in Ancient Rome were made of calcareous rocks obtained from local sources of natural stone, with additions of crushed brick, tile and pottery creating coloured shades of, predominantly, black, red, white, blue and yellow [13]. Polychrome patterns were the most common ones; however monochrome examples are also known [14].

Analyzing individual tesserae in order to know the composition of the base material, and the compound(s) responsible to give the characteristic color to each piece, is an interesting challenge from the chemical and archaeological point of view.

In the specific case of Pompeii, nowadays very serious degradation problems can be identified. For this reason, many houses of the archaeological site need an analytical study which could allow the conservators to guide towards the approach of effective and long-lasting rehabilitation interventions. But despite this need, nowadays it is not possible to collect samples for laboratory analyses purposes. Therefore, the use of portable analytical instrumentation is essential to perform non-destructive in situ analysis. Raman spectroscopy has been applied in the last years for the molecular characterization of Roman mosaics [12, 15-17]. Previous works showed that Raman spectroscopy not only can be used to characterize the base material, but also to identify colorants and opacifiers present within the matrix mosaic tesserae [18]. Apart from those, mosaics from other locations around the world such as Lisbon (Portugal) [19], Guangxi (China) [20], Daphni (Greece) [21] or Ifriqiya (Tunisia) [22] have been characterized by means of Raman spectroscopy. This variety of works evidences the usefulness, powerfulness and robustness of Raman spectroscopy in order to characterize mosaic tesserae, since calcareous, glassy or mineral-based compounds can be detected by this technique. For this reason, in this work Raman spectroscopy was selected as main analytical technique to identify the used base material and the applied pictorial layer of different colored tesserae.

Apart from Raman spectroscopy, Diffuse Reflectance Infrared Transform spectroscopy (DRIFTS) can be also used as supporting technique. The use of DRIFTS to complement the results obtained by means of Raman spectroscopy could permit a secure identification of the compounds present in the mosaic. In the literature there are not works dealing with the use of portable infrared spectrometers applied in situ for the characterization of mosaics. Instead of diffuse reflectance, a spectroradiometer covering the visible, the near infrared, and the short wave infrared $(350-2500 \mathrm{~nm}$ ) has been used in a previous work [23].

Regarding the elemental analysis, $\mathrm{X}$ ray fluorescence spectrometry (XRF) could be one of the best options due to its non-destructive feature and the reliable qualitative and/or semi-quantitative information that can be obtained. In this sense, XRF has been already applied in the analysis of colored tesserae of mosaics to establish the compositional major and minor elements. In some works $[11,12]$, the composition of white and black materials used to manufacture tesserae was determined preparing samples as cross sections and analyzing them using different benchtop instruments, such as a scanning electron microscope coupled to an energy dispersive X-ray spectrometer (SEM-EDS), an XRF spectrometer and an X-ray diffractometer. In this sense, limestone for the white tesserae and tephritic lava for the black tesserae were identified [11]. On the other hand, other research works [24-26] used portable non-invasive techniques in order to characterize in situ the materials used in the decoration objects. Concretely in these latter works [2426] some tesserae from a mosaic located in the Domus of Octavius Quartio (Pompeii) were analyzed with portable instrumentation obtaining interesting results.

If spectroscopic techniques are selected to analyze mosaic tesserae, the obtained data can be treated with statistical tools, such as principal component analysis (PCA), in order to extract more information. PCA obtained using elemental data (mainly obtained by XRF) 
have been applied in archaeological analysis, particularly in trace analysis of ochre pigments $[27,28]$. In our work, this strategy was considered of interest for the analysis of the elemental composition of the tesserae under study.

Pompeian mosaics have not been deeply analyzed from a chemical point of view in the literature. In fact, there is only few works $[12,25,26]$ in which the chemical composition of some tesserae from Pompeian mosaics had been analyzed. Therefore, the available information about the materials used to manufacture the tesserae that were used to create the final Pompeian mosaics is few. Moreover, to manufacture colored tesserae it is supposed that pigments were used. For this reason it is interesting to analyze both the substrate matrix and the pictorial layer of the tesserae. These identifications could help to understand more about the custom procedures and materials used to manufacture Pompeian mosaics.

In this work, to gain knowledge about the materials used to create Pompeian mosaics, two mosaics exposed to the open air and suffering the indirect impact of the rainwater located in rooms $E$ and $G$ of the House of Gilded Cupids (Reg VI, Ins 16, 7, 38, Archaeological Park of Pompeii) were analyzed in situ with non-invasive portable instruments. Raman spectroscopy, supported with DRIFTS, was used as the main analytical technique to ascertain the molecular composition of both the matrix of the used tesserae and the existing pictorial layers. The elemental analysis was performed by means of handheld energy dispersive X-ray fluorescence spectrometry (HH-EDXRF) and Laser Induced Breakdown Spectroscopy (LIBS). The data matrix obtained after XRF measurements was subjected to multivariate analysis (PCA) to observe similarities/differences between tesserae of different colors, while LIBS results were used to estimate the thickness of the applied pictorial layers.

\section{Experimental}

\section{The "House of Gilded Cupids"}

The House of Gilded Cupids (Regio VI, Insula 16) is one of the most important houses of the ancient Pompeii due to the presence of mosaics, magnificent wall paintings and two shrines (Roman and Egyptian). Moreover, it is one of the few houses inside the Archaeological Park of Pompeii (together with the ones of House of Efebo and the Domus of Euplia) that retain two wall mirrors [29].

\section{Mosaic description}

The two mosaics considered in this work are located in room $\mathrm{E}$ and room $\mathrm{G}$ (see Fig. 1).

As can be observed in Fig. 1, the mosaics present in the House of Gilded Cupids show mainly four different colored tesserae: black, red, orange and white. Regarding red and orange tesserae, taking the advantage that some of them were spontaneously detached, a visual inspection was performed, observing that the red and orange colors were obtained applying a pictorial layer (see Additional file 1: Figure S1). The tessera photographed for this work was returned to its original position. The combination of the four different colored tesserae allowed creating a figurative decoration inside a perimetric geometric design (see Fig. 1).

Taking into account that some restoration works were performed in the past in order to preserve the mosaics, with the advice of Archaeological Park of Pompeii, not intervened areas were selected in order to perform the analyses. Before performing the measurements, in order to not affect the analytical results, the tesserae were carefully cleaned using a dry paper tissue to remove all the possible dust and depositions present in the surface of tesserae.

\section{Instrumental}

\section{Portable Raman spectrometer}

Raman analysis was carried out using a portable innoRam spectrometer (B\&WTEKINC., Newark, USA), equipped with a $785 \mathrm{~nm}$ excitation laser. The laser power is $350 \mathrm{~mW}$ at the source and approximately about $200 \mathrm{~mW}$ at the surface of the analyzed sample. The spot size achieved using the probe was of $85 \mu \mathrm{m}$. The instrument implements a controller of the laser power fixable from 100 to $1 \%$ of the laser. The spectral range acquired was between 65 and $3000 \mathrm{~cm}^{-1}$ with a resolution of $4 \mathrm{~cm}^{-1}$ at $912 \mathrm{~nm}$. The instrument implements a TE cooled $\left(-20{ }^{\circ} \mathrm{C}\right)$ back-thinned, 2D binning CCD detector. Raman spectra were recorded using the BWSpecTM 3.26 software version (B\&W Tek Inc.) [30], after a daily calibration with a silicon chip using the $520.5 \mathrm{~cm}^{-1}$ Raman line. The interpretation of the unknown spectra was carried out by comparison with the collected Raman spectra of pure standard compounds inside the e-VIS$\mathrm{NICH}$ dispersive Raman database [31]. Additionally, free available Raman databases [32] and RRUFF [33] were also considered for the assignation of the Raman bands. In total, more than 100 spots were measured during in situ analyses, in order to guarantee representativeness of the acquired spectral information about the mineralogical composition.

\section{Portable infrared spectrometer with a DRIFT sampling interface}

Diffuse reflectance infrared spectra were acquired with a 4100 Exoscan hand-held FTIR spectrometer (Agilent) using a diffuse reflectance sampling interface. The Michelson interferometer has a maximum resolution of $4 \mathrm{~cm}^{-1}$ and a maximum spectral range of $4000-600 \mathrm{~cm}^{-1}$. The spectra were acquired under 32 accumulations, 

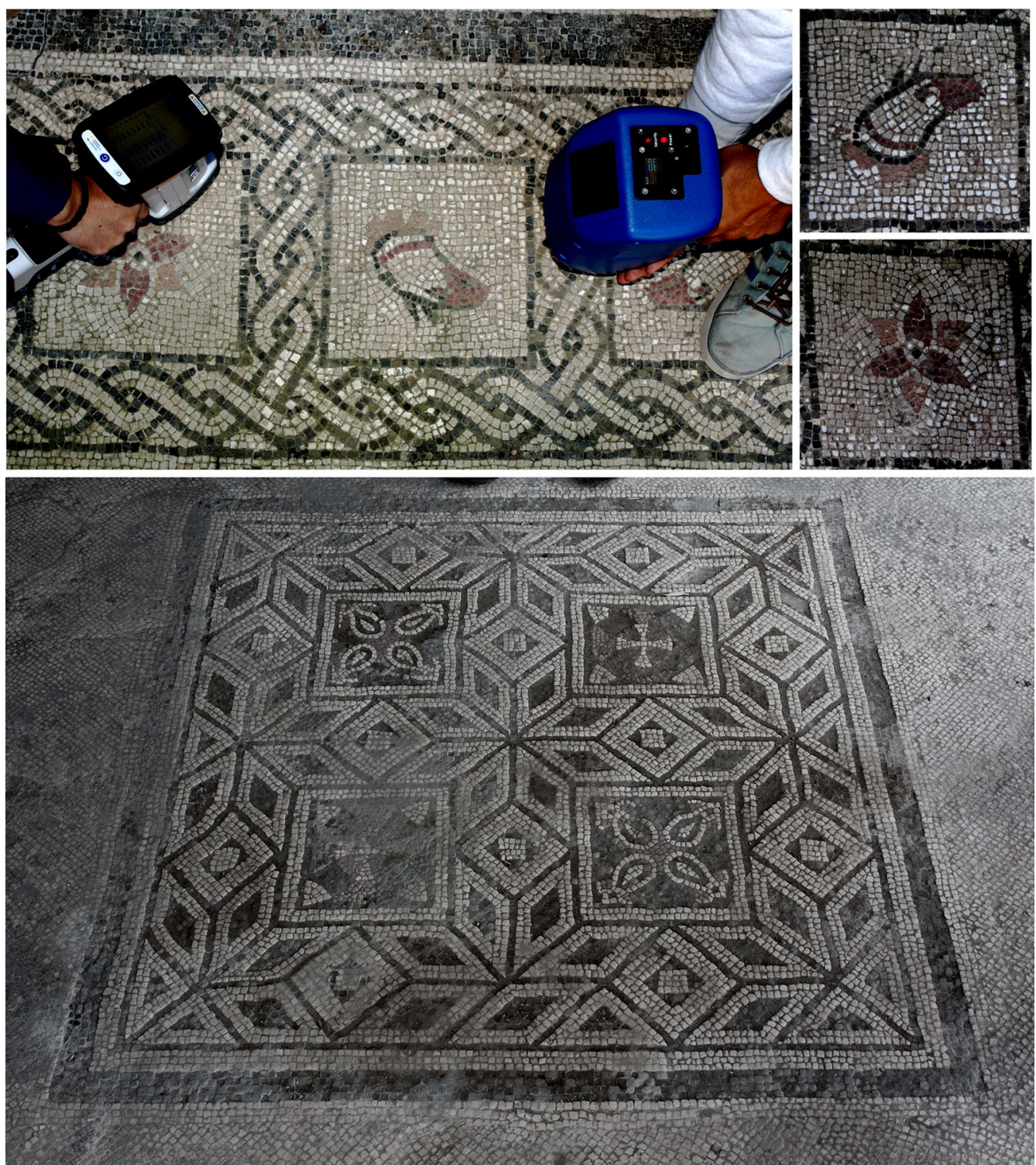

Fig. 1 Part of the mosaic under study located in room E with additional details showing black, red, orange and white tesserae (up) and analyzed mosaic placed in room $\mathrm{G}(\mathrm{down})$

with a spot size of around $2 \mathrm{~mm}$. The system has a $\mathrm{ZnSe}$ beam splitter and a DTGS detector. The background was acquired with a diffuse gold reference cap. In both cases, analysis and the spectra treatment were performed using Nicolet Omnic 7.2 software (Madison, WI, USA).

\section{Hand-held energy dispersive $X$-ray fluorescence spectrometer (HH-EDXRF)}

For the in situ elemental characterization of the mosaics, an XMET7500 (Oxford Instruments, UK) HH-EDXRF was used. The instrument is equipped with a $\mathrm{Rh}$ tube working at a maximum voltage of $45 \mathrm{kV}$. The size of the emitted X-ray beam is $9 \mathrm{~mm}$. The analyzer includes a silicon drift detector (SDD) of high resolution that is able to provide an energetic resolution of $150 \mathrm{eV}$ (FWHM of the $\mathrm{Mn} \mathrm{K} \alpha$ line). The analyzer contains a PDA to control the spectrometer and also to save the spectral and quantitative information. In order to determine possible contributions from the set up of the instrument (e.g. detector) and possible contaminations coming from the XRF analyzer window, 20 repetitive spectra of an instrumental blank (a PTFE block) were acquired before each measurement batch. To determine the presence of the heaviest elements $(\mathrm{Z}>\mathrm{Ti})$, the spectra were acquired during $100 \mathrm{~s}$ 
(real time) and the voltage and current of the X-ray tube were set at $40 \mathrm{kV}$ and $15 \mu \mathrm{A}$ respectively $[34,35]$. Additionally, to remove the "pinches" Bremsstrahlung and 3rd generation peaks, a $500 \mu \mathrm{m} \mathrm{Al}$ filter was used. In order to improve the detection of the lighter elements $(\mathrm{Z}<\mathrm{Ti})$, additional measurements were performed without the $\mathrm{Al}$ filter and at lower voltage $(13 \mathrm{kV})$ and higher current $(40 \mu \mathrm{A})$. The test time in this case was $35 \mathrm{~s}$ for each measurement. See more details elsewhere [36].

\section{Laser induced breakdown spectrometer (LIBS)}

Additional elemental studies were performed using the EasyLIBS IVEA (model Easy 2C) LIBS spectrometer. This instrument employs a pulsed Nd:YAG laser, with the possibility of operating in a dual pulse mode, emitting at a wavelength of $1064 \mathrm{~nm}$. The laser energy per pulse on the sample is higher than $25 \mathrm{~mJ}$ with a repetition rate of $1 \mathrm{~Hz}$ and 4-5 ns duration of laser pulse. Measurements were performed with the double pulse mode. An optimized delay time of $50 \mu$ s to the laser pulse and a gate width of $5 \mathrm{~ms}$ were employed. Considering that LIBS measurements produces the ablation of a very thin layer of material (a micro crater of around $250 \mu \mathrm{m}$ of diameter and $5 \mu \mathrm{m}$ depth), about 30 pulses were performed consecutively at the same point of interest in order to evaluate the stratigraphic evolution of the elements (mainly Fe and $\mathrm{Ca}$ ) that compose the analyzed matrix. The Easy $2 \mathrm{C}$ model consists of an optic probe that allows focusing the laser connected to a computer and to three spectrometers, covering ultraviolet (UV, 196-419 nm), visible (VIS, 420-579 nm) and near infrared (NIR, 580-1000 nm) spectral ranges. The software used for automatic acquisition, control, visualization and processing of the spectra was the AnaLIBS version 6.3. The analyses were performed directly placing the sampling interface on the surface of the tesserae. Taking into account the signalto-noise ratio of the collected LIBS spectra, only peaks whose intensity was greater than a threshold of $0.5 \sigma$ of the total spectrum (under 150-200 counts) were considered for line determination.

\section{Results and discussion}

\section{Molecular characterization of the mosaics}

The different colors (white, orange, red and black) of the mosaics were analyzed in situ in order not only to obtain the mineralogical composition but also to understand the compounds used to give the different colors to each tessera. The discussion of the obtained results is grouped according to the color of the analyzed tesserae.

\section{Red and orange tesserae}

Raman measurements of the red and orange colored tesserae offered the typical spectrum of hematite as shown in Fig. $2\left(\mathrm{Fe}_{2} \mathrm{O}_{3} ; 227,291,411\right.$ and $609 \mathrm{~cm}^{-1}$ bands $[1,5])$ and calcite $\left(\mathrm{CaCO}_{3} ; 155,282,712\right.$ and $1086 \mathrm{~cm}^{-1}$ bands [5]).

The use of hematite in Ancient Roman period is well known and has been widely identified in previous works. Moreover, its use in Pompeii has been clearly proven in the literature $[1,4,5,37-40]$. Therefore, Raman results suggest that these reddish colored tesserae were obtained by using hematite red pigment layer applied over a calcite-based tessera. On the other hand, the spectra acquired by DRIFT spectroscopy, only showed the presence of calcite (see Additional file 1: Figure S2). Hematite is difficult to detect by means of DRIFTS because the main bands of red iron oxide are present in the $400-700 \mathrm{~cm}^{-1}$ spectral region. In this spectral region the energy falls down in the portable infrared spectrometer, thus it is not possible to detect any band in this wavenumber region. Thereby it was not possible to detect hematite by means of DRIFT portable spectrometer, but its presence in red and orange pictorial layers was clearly proven by means of Raman spectroscopy.

\section{White tesserae}

White mosaics, however, were composed mainly by a calcite-based matrix without the application of any pictorial layer, as shown in the obtained Raman spectrum. In Additional file 1: Figure S3 the typical bands of calcite at 282, 712 and $1086 \mathrm{~cm}^{-1}$ [5] can be observed. In this case no additional colored compounds apart from calcite were detected, suggesting that the molecular composition of these white tesserae consisted only in calcite. As observed in previous works [11, 17], in Roman white tesserae the presence of calcite-bearing rock was clearly and frequently identifiable as the mineral constituting the substrate. In this case, pictorial layers were not added to obtain different colored hues.

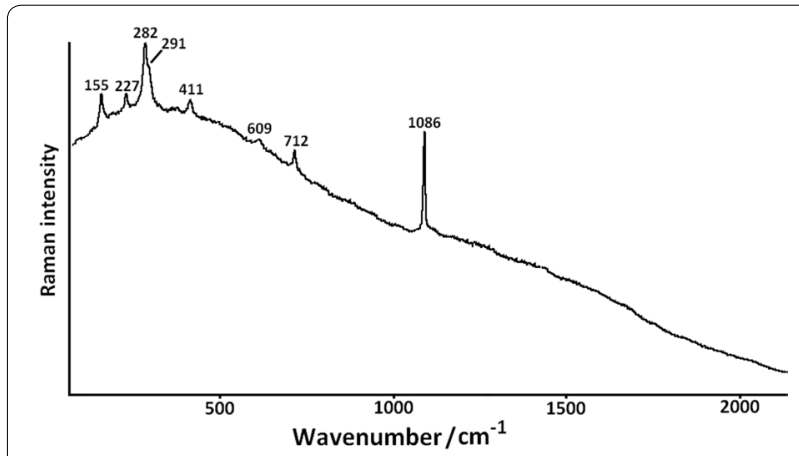

Fig. 2 Representative Raman spectrum of red and orange colored mosaic tesserae 
Apart from calcite, gypsum $\left(\mathrm{CaSO}_{4} \cdot 2 \mathrm{H}_{2} \mathrm{O}\right)$ was also punctually identified $\left(415,1008\right.$ and $1136 \mathrm{~cm}^{-1}$ Raman bands [5], see Fig. 3).

Since the tesserae were subjected to a previous cleaning process, this gypsum could belong to a degradation process that is taking place in the calcite matrix of the tesserae with environmental factors such as $\mathrm{SO}_{\mathrm{x}}$ gases present in the past and current Pompeian atmosphere. These $\mathrm{SO}_{\mathrm{x}}$ gases, when oxidised, form $\mathrm{H}_{2} \mathrm{SO}_{4}$ aerosols with the rain water that impact mosaics, producing the degradation process of the calcite into gypsum, which it is soluble in water. This is one of the most dangerous degradations due to the fact that it might jeopardize the structure of tesserae, making possible the loss of material due to the water soluble gypsum formation. However, the presence of gypsum was only punctually detected, suggesting that this deterioration process has not affected the integrity of the matrix. Even so, the presence of this degradation product should be taken into account and some protection actions should be considered in order to protect the tesserae for their adequate preservation. Elemental data acquired by HH-EDXRF revealed also higher net counts of sulphur in specific areas of the measured white tesserae (see Additional file 1: Figure S4), reinforcing the molecular evidences about sulphates punctual presence.

DRIFTS analysis confirmed Raman results since all the acquired spectra matched perfectly with the DRIFT spectrum of calcite standard (see Fig. 4). In this case, gypsum was not detected. Considering that the presence of this sulphate is punctual and also that with the DRIFT sampling interface the measured area is higher $(2 \mathrm{~mm})$ than the Raman spot size $(85 \mu \mathrm{m})$, the presence of this sulphate at minor/trace level can be diluted in the calcite matrix measured area giving rise to the non-detection of gypsum.

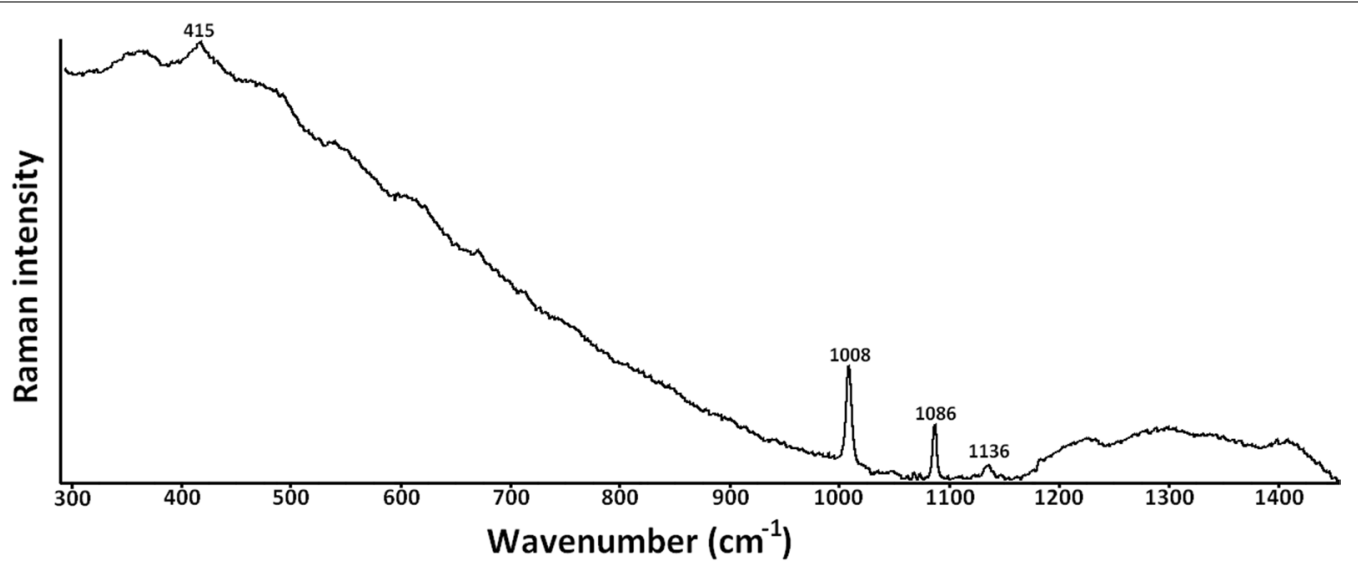

Fig. 3 Raman spectrum obtained punctually in white mosaic tesserae

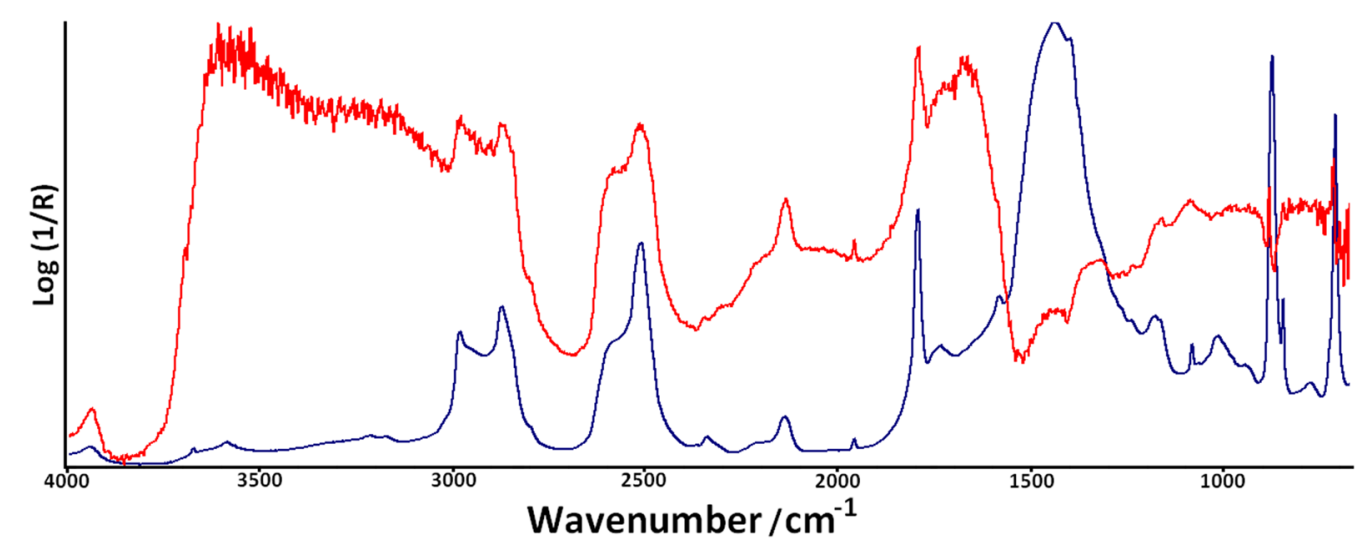

Fig. 4 Representative DRIFT spectrum of white mosaic tesserae (red) and calcite standard (blue) 

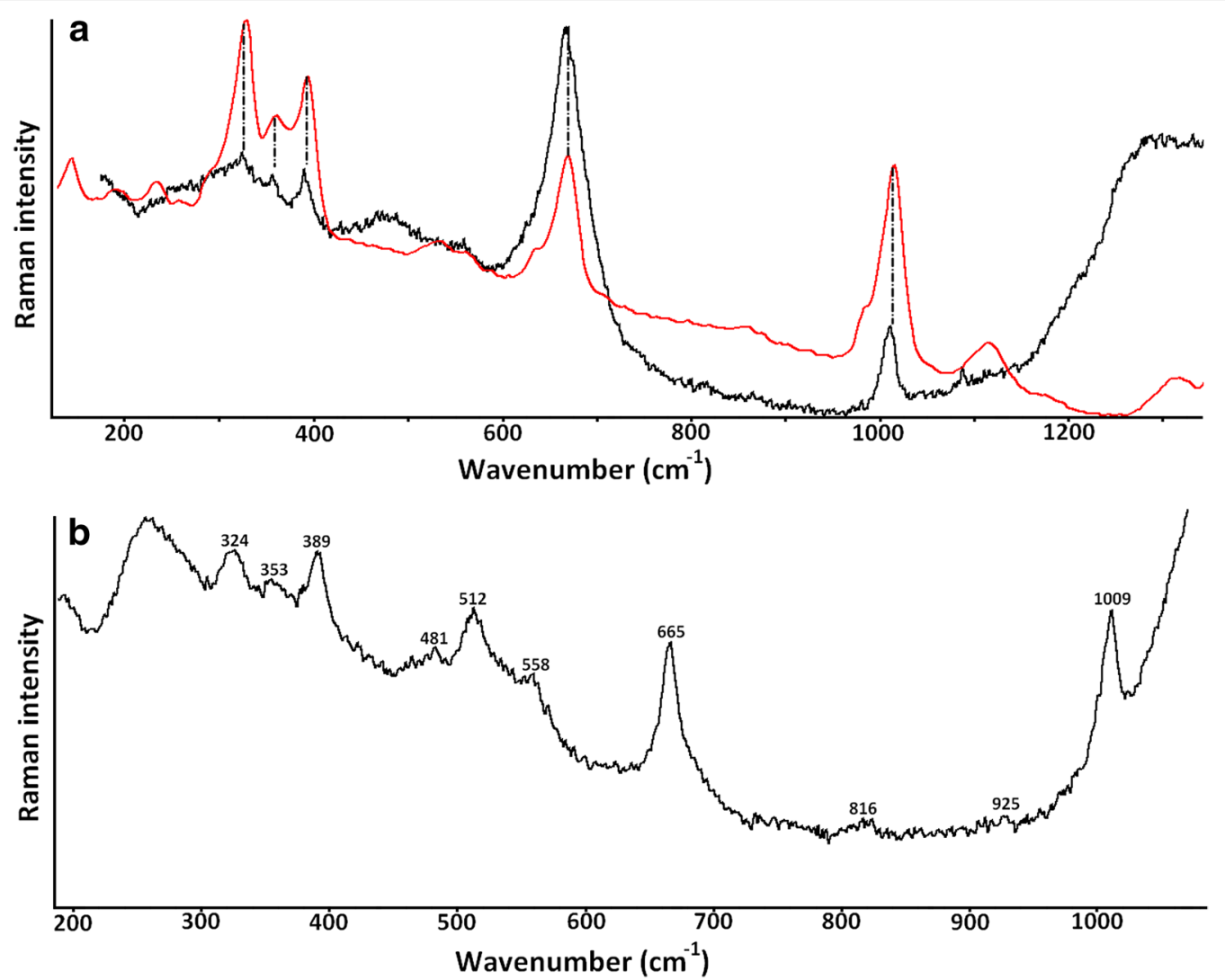

Fig. 5 a Raman spectrum of black colored mosaic tesserae (black) and diopside standard (red) and $\mathbf{b}$ another Raman spectrum of black colored mosaic tesserae

\section{Black tesserae}

The acquired Raman spectra of black tesserae showed the typical feature of a silicate-bearing material (see Fig. 5), most probably from local black-colored volcanic rocks.

The closeness to Mount Vesuvius completely influences the topography and the geological composition of the soils of Pompeii and surroundings. The presence of volcanic and igneous rocks creates a dark landscape, because usually the color of this type of rocks is black. In this sense, diopside $\left(\mathrm{CaMgSi}_{2} \mathrm{O}_{6}\right)$ is a very common rock-forming mineral that gives black color to many igneous rocks. Moreover, this clinopyroxene has been recognised in the composition of the Vesuvian lavas and pyroclastic materials [41-43]. As can be observed in Fig. 5a, the obtained representative spectra of the black tesserae fit with the diopside standard spectrum, confirming the presence of this compound widely present in the tephritic lava from Mount Vesuvius. Apart from that, feldspar, with the most intense peaks at 481 and $512 \mathrm{~cm}^{-1}[44,45]$ could be also present in the composition of black tesserae, as shown in Fig. 5b, in which those commented bands related to feldspar and others related to diopside can be observed. Feldspars also represent one of the main constituent of Vesuvian rocks, therefore its presence, together with the one of diopside, points out the local origin of the material used for black tesserae, as a previous work already have demonstrated [11]. In the same figure, bands at 665 and $324 \mathrm{~cm}^{-1}$ could also suggest the presence of magnetite $\left(\mathrm{Fe}_{3} \mathrm{O}_{4}\right)$ [46] .

Apart from the previously identified volcanic compounds, which were extensively detected, in some spots also leucite was detected (see Additional file 1: Figure S5). Leucite has also been identified as a ubiquitous component in the area of Mount Vesuvius [47], which once again confirms the local origin of the material used for the black tesserae.

\section{Elemental characterization of the mosaics}

As mentioned before an in situ elemental characterization was performed by means of HH-EDXRF to study possible similarities/differences on the elemental composition of the colored mosaics. For that, four to nine measurements in different tesserae of the same color were performed to have a big enough replicate measurements from each type of tesserae. Thanks to that, representative 
analysis and further chemometric data treatment were performed.

The multivariate analysis was performed by means of PCA using the raw net counts of the detected elements. In previous works $[3,36]$, a normalization of the net counts was applied to correct the obtained intensities against (a) the line of one element that showed constant levels in all the samples or (b) the Compton line. In this work, two datasets were performed to compare which one offered the best and most realistic results: one composed by the raw net counts and another dataset with the normalized net counts. As the signal of each element showed high variability depending on the color of the analyzed tessera, the normalization process gave bad PCA results with low explained variance, deciding in this sense to construct the data matrix using the raw net counts of the K $\alpha$ line of each element or the L $\alpha$ line in the case of $\mathrm{Pb}$. The PCA obtained using the raw net counts dataset (23 samples and 17 variables) showed a real and faithful image of the elemental composition of the mosaic tesserae, with an explained variance of $72 \%$ (see Fig. 6).

As shown in Fig. 6, PC1 divides white, orange and red mosaic tesserae (placed in the negative part) from those of black color (in the positive part). The obtained PCA showed that black mosaic tesserae are the ones with the highest level in metals such as $\mathrm{Al}, \mathrm{Si}, \mathrm{K}, \mathrm{Ti}, \mathrm{V}, \mathrm{Fe}, \mathrm{Cu}$, $\mathrm{Zn}, \mathrm{Rb}, \mathrm{Sr}$ and $\mathrm{Zr}$. Most of these metals are highly present in rocks of volcanic origin, particularly from the Somma-Vesuvius area [41]. Moreover, the presence of these elements come in agreement with the compounds identified molecularly by Raman spectroscopy, such as diopside which is a silicate with magnesium (not detectable by means of HH-EDXRF) and calcium, which in the PCA is placed together with white and orange tesserae since their are composed by a calcitebased matrix. According to the literature [48], the volcanic material and tephritic lava from Mount Vesuvius is composed by $\mathrm{K}, \mathrm{Ti}, \mathrm{Cu}, \mathrm{Zn}, \mathrm{Rb}, \mathrm{Sr}$ and $\mathrm{Zr}$ at minor/ trace levels. Thus, the presence of these elements confirm the previous Raman results and demonstrate that black color was achieved using local black colored rocks present in the vicinities of Mount Vesuvius.

White colored mosaics presented higher levels of $\mathrm{Ca}$, $\mathrm{P}$ and in a minor extent, $\mathrm{Mn}$. The major element was calcium as expected, because white mosaic tesserae were manufactured by a calcite-based matrix, as shown in the results obtained by Raman spectroscopy. Thus, elemental measurements corroborate the previous results. Moreover, unlike black tesserae, white ones do not present any of the previously mentioned elements

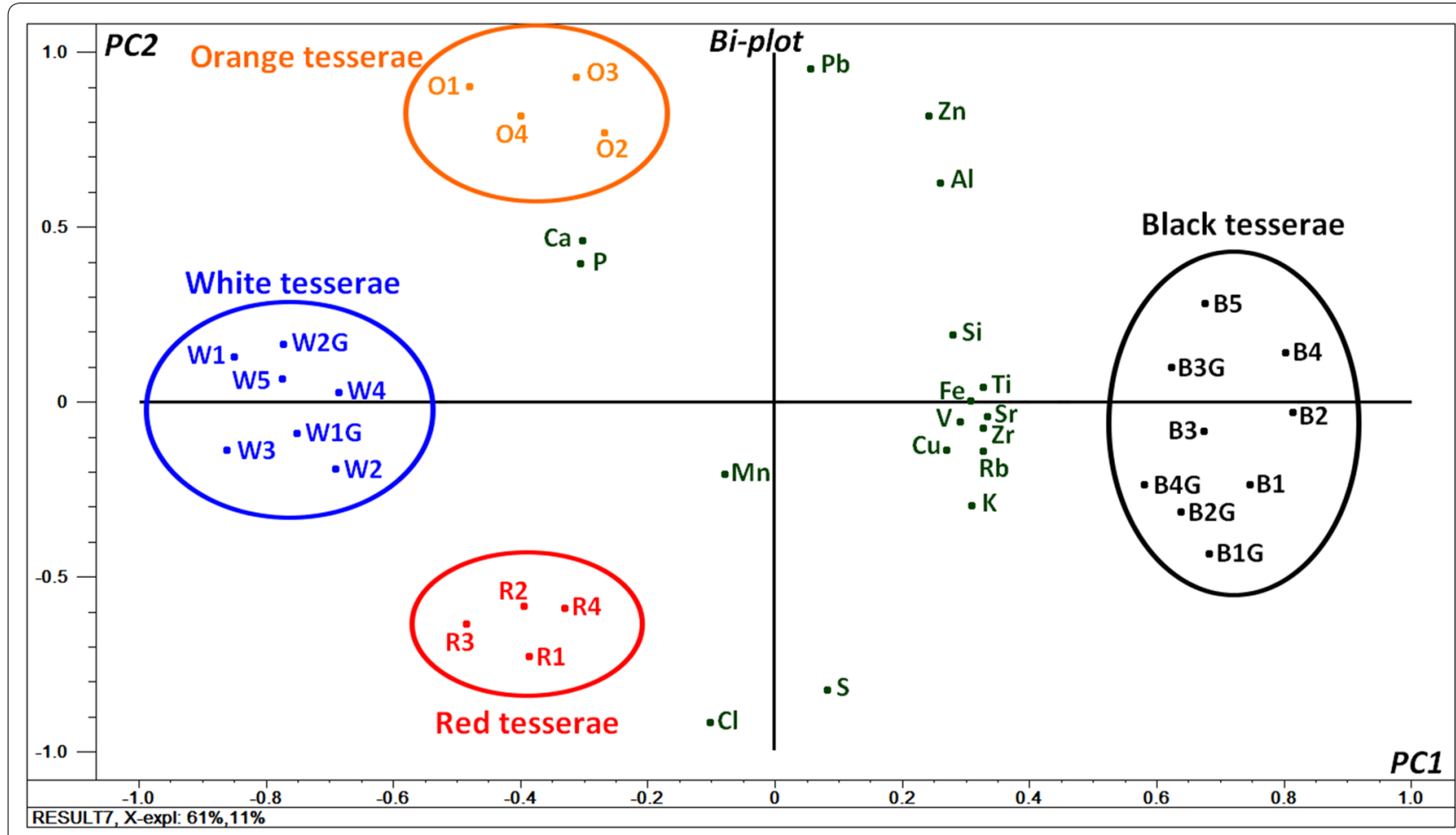

Fig. 6 Projection of the scores and loadings (bi-plots) on PC1-PC2 obtained from the PCA with all the HH-EDXRF measurements performed on the white $(\mathrm{W})$, orange $(\mathrm{O})$, red $(\mathrm{R})$, and black $(\mathrm{B})$ mosaic tesserae from the room $\mathrm{E}$, and room $\mathrm{G}$ (measurements of this last room marked with a $\mathrm{G}$ ) of the House of Gilded Cupids 
related with volcanic origin in significantly high levels. Instead of them, white tesserae together with the orange ones, presented the highest level of $\mathrm{P}$ and $\mathrm{Mn}$ among all the analyzed tesserae. However, the intensity of the $\mathrm{K}_{\alpha}$ line of $\mathrm{P}$ and $\mathrm{Mn}$ was very low in all the cases. The case of $\mathrm{Cl}$ in red tesserae was exactly the same as the previous one.

As stated previously, white, orange and red tesserae are placed in the same part of the PC1. This is probably due to the common calcite-based matrix. However, there are significant differences in the PC2 axis. In our opinion, the amount of hematite (Fe mainly) explains such differences, because (a) the white tesserae did not have iron, and (b) the amount of $\mathrm{Fe}$ in the red tesserae is much higher than in the orange ones.

To confirm the reasons for such differences between red and orange tesserae, the mean value of $\mathrm{Fe} / \mathrm{Ca}$ net counts ratio was calculated from these two tesserae (see Additional file 1: Figure S6). As shown in the figure, the orange colored samples have a lower level of $\mathrm{Fe} / \mathrm{Ca}$. The obtained mean value of $\mathrm{Fe} / \mathrm{Ca}$ normalized net counts for red tesserae was $0.26 \pm 0.04$, while for orange ones was $0.15 \pm 0.04$. Thus, these results confirm that orange color was obtained by using less quantity of hematite or diluting it within the calcite matrix of the mosaic.

Finally, LIBS was used to approach the thickness of the applied pictorial layer in the case of red colored tesserae. For that, a certain red tessera was selected and subsequent pulses were performed in the same point of analysis. In order to assess the pictorial layer thickness, the levels of $\mathrm{Ca}$ and $\mathrm{Fe}$ were monitored using their characteristic lines at 393.2 and $374.55 \mathrm{~nm}$ respectively. As shown in Additional file 1: Figure S7, both Fe and Ca levels are maintained constant in the applied 28 pulses, suggesting that there is no change in the in-depth levels of both elements. This means that no layer change was observed in the subsequent analyses. Therefore, taking into account that in 28 LIBS pulses approximately about $140 \mu \mathrm{m}$ were penetrated, it points out that the pictorial layer is thicker than this.

\section{Conclusions}

This work allowed obtaining, without sampling and only using portable instrumentation, useful information about the materials used to manufacture colored tesserae of mosaics from the House of Gilded Cupids in Pompeii. In this sense, in order to obtain white color tesserae calcitebearing rocks were used. On the other hand, in order to achieve the black color, instead a calcite-based matrix, lava pieces from Mount Vesuvius activity containing diopside, feldspar, leucite and magnetite, were used. Therefore, it can be affirmed that the artists used the local mineral resources in order to produce the materials that they needed for their works, as previous works already demonstrated [11, 49]. Reddish and orange hues were obtained by using hematite pictorial layer over the calcite based tessera. Orange color was obtained diluting in a calcite matrix the used hematite pigment. The applied hematite pictorial layer was thicker than $140 \mu \mathrm{m}$ as showed the in-depth LIBS analysis.

Apart from that, the punctual presence of gypsum was identified in some white tesserae. This sulphate is probably present due to a degradation process involving the $\mathrm{SO}_{\mathrm{x}}$ gases present in the actual polluted atmosphere, which with the rain water can react with the calcite matrix of the tesserae, producing gypsum. Since gypsum is soluble in water, a loss of the material of the tesserae could be produced, jeopardizing those mosaics which are exposed to the rainfalls. Therefore, extreme care must be taken to preserve this type of ancient artworks.

Regarding the molecular non-invasive techniques used in this work, Raman spectroscopy provided much more results than DRIFTS, which only offered information about calcite presence in white tesserae. Thanks to Raman spectroscopy typical volcanic compounds (diospside, leucite, feldspar, and magnetite) were identified in the black tesserae and hematite as colorant agent in red and orange ones. In the case of white tesserae, gypsum was detected by means of Raman spectroscopy but not by DRIFTS. Thus, this work demonstrated that in this case Raman spectroscopy is a more appropriate technique than DRIFTS-which showed great limitations, since this latter technique was not able to offer signals of compounds that are present in the sample.

\section{Additional file}

Additional file 1: Figure S1. Detached red tessera from the mosaic. Figure S2. Representative DRIFT spectra of red and orange tesserae (red) and calcite standard (black). Figure S3. Representative Raman spectrum of white tesserae. Figure S4. Normalized net counts of S in different white tesserae. Figure S5. Representative Raman spectrum of black tesserae and leucite standard. Figure S6. Mean values of Fe/Ca normalized net counts of red and orange colored tesserae. Figure S7. Ca and Fe lines intensity variation after 28 shots obtained by means of LIBS.

\section{Authors' contributions}

$\mathrm{HM}$ and IM performed the XRF analysis. NPT and MM performed the Raman analysis. MV and SFOV performed the LIBS measurements and interpretations. $\mathrm{AM}$ and $\mathrm{BN}$ supervised the measurement processes to guarantee the absence of damage to the mirrors. MO and JMM designed and supervised the whole project. IM and MM wrote the initial draft of the manuscript. All authors read and approved the final manuscript.

\section{Author details}

${ }^{1}$ Department of Analytical Chemistry, Faculty of Science and Technology, University of the Basque Country UPV/EHU, P.O. Box 644, 48080 Bilbao, Basque Country, Spain. ${ }^{2}$ Department of Analytical Chemistry, Faculty of Pharmacy, 
University of the Basque Country UPV/EHU, P.O. Box 450, 01080 Vitoria-Gasteiz, Basque Country, Spain. ${ }^{3}$ Department of Condensed Matter Physics, University of Valladolid (UVa), Valladolid, Spain. ${ }^{4}$ Applied Research Laboratory of Archaeological Park of Pompeii, via Plinio 4, 80045 Pompeii, NA, Italy. ${ }^{5}$ Archaeological Park of Pompeii, via Plinio 4, 80045 Pompeii, NA, Italy. ${ }^{6}$ Unesco Chair of Cultural Landscapes and Heritage, University of the Basque Country UPV/EHU, P.O. Box 450, 01006 Vitoria-Gasteiz, Basque Country, Spain.

\section{Acknowledgements}

We want to thank gratefully the "Archaeological Park of Pompeii" for the permissions given to analyze in situ the mosaics of the studied house. Iker Marcaida is grateful to the Basque Government who funded his predoctoral fellowship. This work has been supported by the project MADyLIN (BIA201787063-P) funded by the Spanish Agency for Research AEI (MINEICO-FEDER/ UE).

\section{Competing interests}

The authors declare that they have no competing interests.

\section{Availability of data and materials}

All data generated or analyzed during this study are included in this published article and its Additional files.

\section{Publisher's Note}

Springer Nature remains neutral with regard to jurisdictional claims in published maps and institutional affiliations.

\section{Received: 19 October 2018 Accepted: 10 January 2019}

Published online: 22 January 2019

\section{References}

1. Marcaida I, Maguregui M, Morillas H, Prieto-Taboada N, de Vallejuelo SF, Veneranda M, Madariaga JM, Martellone A, De Nigris B, Osanna M. In situ non-invasive characterization of the composition of Pompeian pigments preserved in their original bowls. Microchem J. 2018;139:458-66.

2. Marcaida I, Maguregui M, Morillas H, García-Florentino C, Knuutinen U, Carrero JA, de Vallejuelo SF, Pitarch-Marti A, Castro K, Madariaga JM. Multispectroscopic and isotopic ratio analysis to characterize the inorganic binder used on Pompeian pink and purple lake pigments. Anal Chem. 2016:88:6395-402.

3. Madariaga JM, Maguregui M, Castro K, Knuutinen U, Martínez-Arkarazo I. Portable Raman, DRIFTS, and XRF analysis to diagnose the conservation state of two wall painting panels from pompeii deposited in the Naples national archaeological museum (Italy). Appl Spectrosc. 2016;70:137-46.

4. Marcaida I, Maguregui M, de Vallejuelo SF, Morillas H, Prieto-Taboada N, Veneranda $\mathrm{M}$, et al. In situ X-ray fluorescence-based method to differentiate among red ochre pigments and yellow ochre pigments thermally transformed to red pigments of wall paintings from Pompeii. Anal Bioanal Chem. 2017;409:3853-60.

5. Aliatis I, Bersani D, Campani E, Casoli A, Lottici PP, Mantovan S, et al. Pigments used in Roman wall paintings in the Vesuvian area. J Raman Spectrosc. 2010;41:1537-42.

6. Marcaida I, Maguregui M, Morillas H, García-Florentino C, Pintus V, Aguayo T, et al. Optimization of sample treatment for the identification of anthraquinone dyes by surface-enhanced Raman spectroscopy. Anal Bioanal Chem. 2017:409:2221-8.

7. Petriaggi R, Mancinelli R. An experimental conservation treatment on the mosaic floor and perimeter walls of room n. 1 of the so-called "Villa con ingresso a Protiro" in The Underwater Archaeological Park of Baia (Naples). Archaeol Marit Mediterr. 2004;1:109-26.

8. Christensen AM. From palaces to Pompeii: the architectural and social context of hellenistic floor mosaics in the house of the Faun. Ph.D. Thesis, Florida State University; 2006.

9. Boschetti C, Leonelli C, Macchiarola M, Veronesi P, Corradi A, Sada C. Early evidences of vitreous materials in Roman mosaics from Italy: an archaeological and archaeometric integrated study. J Cult Herit. 2008;9:21-6.
10. Ricca M, La Russa ME, Ruffolo SA, Davidde B, Barca D, Crisci GM. Mosaic marble tesserae from the underwater archaeological site of Baia (Naples, Italy): determination of the provenance. Eur J Mineral. 2014;26:323-31.

11. Izzo F, Arizzi A, Cappelletti P, Cultrone G, De Bonis A, Germinario C, Graziano SF, Grifa C, Guarino V, Mercurio M, Morra V, Langella A. The art of building in the Roman period ( $89 \mathrm{BC}-79 \mathrm{AD})$ : mortars, plasters and mosaic floors from ancient Stabiae (Naples, Italy). Constr Build Mater. 2016;117:129-43

12. Ricciardi P, Colomban P, Tournié A, Macchiarola M, Ayed N. A non-invasive study of Roman Age mosaic glass tesserae by means of Raman spectroscopy. J Archaeol Sci. 2009;36:2551-9.

13. Witts P. Mosaics in Roman Britain. Chicago: Tempus; 2005.

14. Packard P. A monochrome mosaic at Isthmia. Hesperia. 1980;49:326.

15. Gedzevičiūtè V, Welter N, Schüssler U, Weiss C. Chemical composition and colouring agents of Roman mosaic and millefiori glass, studied by electron microprobe analysis and Raman microspectroscopy. Archaeol Anthropol Sci. 2009;1:15-29.

16. Galli S, Mastelloni M, Ponterio R, Sabatino G, Triscari M. Raman and scanning electron microscopy and energy-dispersive $x$-ray techniques for the characterization of colouring and opaquening agents in Roman mosaic glass tesserae. J Raman Spectrosc. 2004;35:622-7.

17. Boschetti C, Corradi A, Baraldi P. Raman characterization of painted mortar in Republican Roman mosaics. J Raman Spectrosc. 2008;39:1085-90.

18. Basso E, Invernizzi C, Malagodi M, La Russa M, Bersani D, Lottici PP. Characterization of colorants and opacifiers in roman glass mosaic tesserae through spectroscopic and spectrometric techniques. J Raman Spectrosc. 2014:45:238-45.

19. Muralha VSF, Canaveira S, Mirão J, Coentro S, Morna T, Salerno C. Baroque glass mosaics from the Capela de São João Baptista (Chapel of Saint John the Baptist, Lisbon): unveiling the glassmaking records. J Raman Spectrosc. 2015;46:483-92.

20. Zhao H, Li Q, Liu S, Gan F. Characterization of microcrystals in some ancient glass beads from china by means of confocal Raman microspectroscopy. J Raman Spectrosc. 2013;44:643-9.

21. Di Martino D, Galli A, Martini M. The intriguing case of silicon crystals unveiled in ancient mosaic tesserae. J Raman Spectrosc. 2012:43:1824-7.

22. Colomban P, March G, Mazerolles L, Karmous T, Ayed N, Ennabli A, Slim $H$. Raman identification of materials used for jewellery and mosaics in Ifriqiya. J Raman Spectrosc. 2003;34:205-13.

23. Lysandrou V, Cerra D, Agapiou A, Charalambous E, Hadjimitsis DG. Towards a spectral library of Roman to Early Christian Cypriot floor mosaics. J Archaeol Sci Rep. 2017;14:782-91.

24. Gill MS, Rehren T. Material characterization of ceramic tile mosaic from two 17th century Islamic monuments in northern India. Archaeometry. 2011;53:22-36

25. Germinario C, Francesco I, Mercurio M, Langella A, Sali D, Kakoulli I, De Bonis A, Grifa C. Multi-analytical and non-invasive characterization of the polychromy of wall paintings at the Domus of Octavius Quartio in Pompeii. EPJ Plus. 2018:133:359.

26. Grifa C, Barba S, Fiorillo F, Germinario C, Izzo F, Mercurio M, et al. The domus of Octavius Quartio in Pompeii: damage diagnosis of the masonries and frescoed surfaces. Int J Conserv Sci. 2016;7:885-900.

27. Popelka-Filcoff RS, Robertson JD, Glascock MD, Descantes C. Trace element characterization of ochre from geological sources. J Radioanal Nucl Chem. 2007:272:17-27.

28. Jercher M, Pring A, Jones PG, Raven MD. Rietveld X-ray diffraction and $X$-ray fluorescence analysis of Australian aboriginal ochres. Archaeometry. 1998:40:383-401.

29. Veneranda M, de Vallejuelo SF, Prieto-Taboada N, Maguregui M, Marcaida I, Morillas H, Martellone A, de Nigris B, Osanna M, Castro K, Madariaga JM. In-situ multi-analytical characterization of original and decay materials from unique wall mirrors in the House of Gilded Cupids, Pompeii. Herit Sci. 2018;6:40

30. Maguregui M, Knuutinen U, Martinez-Arkarazo I, Giakoumaki A, Castro K, Madariaga JM. Field Raman analysis to diagnose the conservation state of excavated walls and wall paintings in the archaeological site of Pompeii (Italy). J Raman Spectrosc. 2012;43:1747.

31. Maguregui M, Prieto-Taboada N, Trebolazabala J, Goienaga N, Arrieta N, Aramendia J, Gomez-Nubla L, Sarmiento A, Olivares M, Carrero JA, Martinez-Arkarazo I, Castro K, Arana G, Olazabal MA, Fernandez LA, 
Madariaga JM. ChemCH 1st international congress chemistry for cultural heritage, Ravenna, 2010; p. 168.

32. Burgio L, Clark RJ. Library of FT-Raman spectra of pigments, minerals, pigment media and varnishes, and supplement to existing library of Raman spectra of pigments with visible excitation. Spectrochim Acta A. 2001;57:1491-521.

33. Downs RT. The RRUFF project: an integrated study of the chemistry, crystallography, Raman and infrared spectroscopy of minerals. In: Program and abstracts of the 19th general meeting of the international mineralogical association in Kobe, Japan, 2006. http://rruff.info. Accessed Jan 2019.

34. Morillas H, Maguregui M, García-Florentino C, Carrero JA, Salcedo I, Madariaga JM. The cauliflower-like black crusts on sandstones: a natural passive sampler to evaluate the surrounding environmental pollution. Environ Res. 2016;147:218-32.

35. Morillas H, García-Galán J, Maguregui M, García-Florentino C, Marcaida I, Carrero JA, Madariaga JM. In-situ multianalytical methodology to evaluate the conservation state of the entrance arch of La Galea Fortress (Getxo, north of Spain). Microchem J. 2016;128:288-96.

36. García-Florentino C, Maguregui M, Morillas H, Marcaida I, Madariaga JM. A fast in situ non-invasive approach to classify mortars from a construction of high historical value. Microchem J. 2017;133:104-13.

37. Castriota M, Cosco V, Barone T, De Santo G, Carafa P, Cazzanelli E. Micro-Raman characterizations of Pompei's mortars. J Raman Spectrosc. 2008;39:295-301.

38. Miriello D, Bloise A, Crisci GM, De Luca R, De Nigris B, Martellone A, Osanna M, Pace R, Pecci A, Ruggieri N. Non-destructive multi-analytical approach to study the pigments of wall painting fragments reused in mortars from the archaeological site of Pompeii (Italy). Minerals. 2018;8:134.

39. Piovesan R, Siddall R, Mazzoli C, Nodari L. The Temple of Venus (Pompeii): a study of the pigments and painting techniques. J Archaeol Sci. 2011;38:2633-43.

40. Giachi G, De Carolis E, Pallecchi P. Raw materials in Pompeian paintings: characterization of some colors from the archaeological site. Mater Manuf Process. 2009;24:1015-22.
41. Santacroce R, Cioni R, Marianelli P, Sbrana A, Sulpizio R, Zanchetta G, Donahue DJ, Joron JL. Age and whole rock-glass compositions of proximal pyroclastics from the major explosive eruptions of Somma-Vesuvius: a review as a tool for distal tephrostratigraphy. J Volcanol Geotherm Res. 2008;177:1.

42. Cioni R, Marianelli P, Santacroce R. Thermal and compositional evolution of the shallow magma chambers of Vesuvius: evidence from pyroxene phenocrysts and melt inclusions. J Geophys Res Solid Earth. 1998;103:18277-94

43. Morra V, Calcaterra D, Cappelletti P, Colella A, Fedele L, De'Gennaro R, et al. Urban geology: relationships between geological setting and architectural heritage of the Neapolitan area. J Virtual Explor. 2010;36:26.

44. Freeman JJ, Wang A, Kuebler KE, Jolliff BL, Haskin LA. Characterization of natural feldspars by Raman spectroscopy for future planetary exploration. Can Mineral. 2008;46:1477-500.

45. Bersani D, Aliatis I, Tribaudino M, Mantovani L, Benisek A, Carpenter MA, Gatta GD, Lottici PP. Plagioclase composition by Raman spectroscopy. J Raman Spectrosc. 2018;49:684-98.

46. Shebanova ON, Lazor P. Raman spectroscopic study of magnetite $\left(\mathrm{FeFe}_{2} \mathrm{O}_{4}\right.$ ): a new assignment for the vibrational spectrum. J Solid State Chem. 2003;174:424-30.

47. Shea T, Larsen JF, Gurioli L, Hammer JE, Houghton BF, Cioni R. Leucite crystals: surviving witnesses of magmatic processes preceding the 79AD eruption at Vesuvius, Italy. Earth Planet Sci Lett. 2009;281:88.

48. Savelli C. The problem of rock assimilation by Somma-Vesuvius magma. Contrib Mineral Petrol. 1967;16:328.

49. Marcaida I, Maguregui M, Morillas H, Veneranda M, Prieto-Taboada N, de Vallejuelo SF, Madariaga JM. Raman microscopy as a tool to discriminate mineral phases of volcanic origin and contaminations on red and yellow ochre raw pigments from Pompeii. J Raman Spectrosc. 2018. https://doi. org/10.1002/jrs.5414.

\section{Submit your manuscript to a SpringerOpen ${ }^{\odot}$ journal and benefit from:}

- Convenient online submission

- Rigorous peer review

- Open access: articles freely available online

- High visibility within the field

- Retaining the copyright to your article

Submit your next manuscript at $\boldsymbol{\nabla}$ springeropen.com 